\title{
Marco jurídico que controla el tráfico ilícito de migrantes y la trata de personas en Nicaragua. Estudio de caso: Puesto Fronterizo Peñas Blancas
}

Heydi José González Briones

Servicio Jesuita para Migrantes - Nicaragua (SJM). Universidad Centroamericana - UCA. Rubén Darío, 500mts al oeste, Managua, Nicaragua. E-mail: heydi85@hotmail.com

Recibido: octubre de 2007 / Aceptado: octubre de 2007

EN ESTE ARTÍCULO SE EXPONE UN ANÁLISIS DEL MARCO JURÍDICO - internacional y nacional - para combatir los delitos de tráfico ilícito de migrantes y trata de personas, que tienen lugar dentro del fenómeno de la migración irregular. Dicho análisis tiene como referencia las particularidades de la migración irregular dentro del territorio nicaragüense - como país emisor de migrantes y como zona de tránsito para migrantes extraregionales. En concreto, nos referimos a los flujos migratorios irregulares que tienen lugar en la frontera sur de Nicaragua - Costa Rica.

En esta frontera existen dos tipos de flujos migratorios: flujo sur-norte, que corresponde a migrantes extra-regionales que se dirigen hacia Estados Unidos y flujo sur-sur, que corresponde a la emigración de nicaragüenses hacia Costa Rica. Estos flujos irregulares son propicios para la comisión de los delitos de tráfico ilícito de migrantes y trata de personas, ambos considerados parte del crimen internacional organizado.

A nivel internacional, los instrumentos legales vigentes tienen por objeto reconocer que la migración en sí misma no es delito y por tanto, no está sujeta a enjuiciamiento penal. Asimismo, enfatizan en el respeto de los derechos y protección de las víctimas e insisten en la no criminalización del migrante.

A nivel nacional, en este artículo, nos referimos con especial atención a la Ley 240 -513, Ley de Control del Tráfico de Migrantes Ilegales y la aplicabilidad de dicha normativa frente a la realidad de la migración irregular: existencia de las redes de traficantes y tratantes de migrantes, el "coyotaje", la falta de experticia policial y judicial para combatir estos delitos, la vulnerabilidad de la población migrante 
irregular e indocumentada, las deficiencias estructurales y las políticas migratorias que vulneran los derechos humanos de la población migrante.

Palabras clave: migración humana / legislación / ilegalidad / Nicaragua-Costa Rica

\section{Introducción}

La inmigración indocumentada ha llegado a niveles sin precedentes: casi 30 millones de personas en todo el mundo carecen de un estatus de residencia legal en el país donde viven (PNUD, 2004). El aumento del número de inmigrantes irregulares o indocumentados tiene su origen en las políticas migratorias con carácter restrictivo que aplican tanto los países de tránsito como los países de acogida de mano de obra inmigrada. Según Lelio Mármora (2002), las políticas de restricción migratoria tienen como objetivo impedir la entrada a un territorio determinado, y se ejecutan a través de diferentes acciones de control que pueden derivar en otras, como el castigo al inmigrante no autorizado o la expulsión del mismo.

La definición de estas políticas gira sobre un permanente juego entre dos tipos de intereses y derechos: el de los Estados y el de la población migrante (Mármora, 2002:284). Estas políticas se desarrollan en un contexto de contradicciones. La inmigración es percibida como una amenaza e incluso como un riesgo para la seguridad nacional, lo que provoca un rechazo de la misma. Pero a la vez, la economía ha ido planteando una demanda creciente de mano de obra inmigrada. En este contexto contradictorio los gobiernos han optado por implementar políticas migratorias de carácter restrictivo, discriminatorio, selectivo, represivo y aleatorio.

La realidad demuestra que la restricción y control de las fronteras no es el mecanismo idóneo para frenar los movimientos migratorios, pues como resultado de este tipo de políticas, los flujos migratorios irregulares aumentan, y por tanto, aumenta la vulnerabilidad de la población migrante durante el proceso migratorio. Este evidente fracaso de las políticas migratorias se debe, entre otras razones, a que éstas no dan respuesta a las raíces de las migraciones: el desequilibrio económico entre los países de origen y destino.

Desafortunadamente, los flujos migratorios irregulares, producto de las políticas migratorias basadas en el control, están siendo aprovechados por las redes del crimen organizado dedicadas al tráfico ilícito de migrantes y la trata de personas. Estas actividades se han convertido en un negocio mundial que genera enormes beneficios para los traficantes y tratantes. Un estudio de la Organización Internacional para las Migraciones (OIM) reveló que existen entre 15 y 30 millones de migrantes irregulares en todo el mundo. De este total, el Departamento de Justicia de los Estados Unidos estima que anualmente 700,000 mujeres y niños son objeto de tráfico a través de las fronteras (OIM, s.f.).

Nicaragua ha sido considerada por el Departamento de Estado de Estados Unidos como fuente y país de tránsito para que mujeres y niños sean víctimas de tráfico y explotación sexual. El Departamento de Estado de Estados Unidos colocó a cada uno de los países 
incluidos en el Informe sobre la Trata de Personas de 2003, en una de tres categorías, denominadas Filas, basadas en el alcance de las medidas tomadas por el gobierno para combatir el problema de la trata de personas. Nicaragua ha sido colocada en la Fila 2, lo que significa que es un país que sí tiene un problema serio de trata de personas, con un número significativo de casos detectados, pero que a la vez está tomando medidas serias de prevención (Romero, 2004).

Nicaragua es un país de origen y tránsito de población migrante. La población nicaragüense emigra principalmente hacia Costa Rica (flujo sur-sur) y Estados Unidos (flujo sur-norte), aunque se ha incrementado la emigración hacia El Salvador. A la vez - por su posición geográfica - Nicaragua es zona de tránsito para ciudadanos suramericanos, asiáticos y africanos que se dirigen hacia los Estados Unidos. El mayor flujo de inmigrantes indocumentados ingresa por el puesto fronterizo de Peñas Blancas en la frontera sur de Nicaragua-Costa Rica. Para regular estos flujos migratorios de tránsito en el territorio, las autoridades implementan una política de restricción migratoria a través de leyes restrictivas y ejerciendo control y restricción en las fronteras. El marco jurídico nicaragüense que controla el tráfico ilícito de migrantes tiene una serie de vacíos y termina penalizando al migrante en lugar de sancionar al traficante.

El abordaje del fenómeno migratorio irregular constituye un reto tanto para los actores públicos como para la sociedad civil organizada y la sociedad en general. En este sentido, el Servicio Jesuita para Migrantes de Nicaragua realizó en 2005 un estudio sobre el tráfico ilícito de migrantes en la frontera de Peñas Blancas (Nicaragua-Costa Rica). Dicho estudio describe el marco jurídico que tipifica, controla y penaliza el tráfico de migrantes, así como el delito de trata de personas; además, analiza la aplicabilidad de esta normativa a la realidad de la migración irregular, las dinámicas que se generan, y las redes dedicadas al "coyotaje" y al tráfico de migrantes.

En el presente artículo describo los principales resultados de dicho estudio. Para esto, tomaré como referencia el marco jurídico internacional y nacional que regula la migración irregular - los flujos irregulares que tienen lugar en la frontera de Peñas Blancas (flujo sur-sur, flujo sur-norte) -, así como la experiencia de los distintos actores involucrados en este fenómeno: migrantes, familiares de migrantes, traficantes/“coyotes”, autoridades de migración y extranjería, autoridades policiales y organizaciones de la sociedad civil.

\section{Marco Jurídico Internacional}

LaConvención de las Naciones Unidascontraladelincuenciaorganizadatransnacional ${ }^{1}$ y sus dos protocolos adicionales se encuentran dentro de los instrumentos jurídicos relevantes para la protección y prevención de violaciones de derechos humanos de los migrantes. Los dos protocolos adicionales a esta Convención, conocidos como los protocolos de Palermo, se refieren al tráfico ilícito de personas y a la trata de personas: Protocolo contra el tráfico ilícito de migrantes por tierra mar y aire y Protocolo contra el tráfico para prevenir, reprimir y sancionar la trata de personas, especialmente mujeres y niños. 
El Protocolo contra el tráfico ilícito de migrantes por tierra, mar y aire ${ }^{2}$, define el delito de tráfico de migrantes como:

La facilitación de la entrada ilegal de una persona en un Estado del cual dicha persona no sea nacional o residente permanente con el fin de obtener, directa o indirectamente, un beneficio financiero u otro beneficio de orden material.

La finalidad de este instrumento es prevenir y combatir el tráfico ilícito de migrantes, así como promover la cooperación entre los Estados Parte, protegiendo los derechos de los migrantes objeto de dicho tráfico. Las medidas que establece este instrumento no tienen por objeto determinar la política interna sobre la migración ni las corrientes migratorias, sino reconocer que la migración en sí misma no es delito y por tanto, no está sujeta a enjuiciamiento penal. En este sentido, los y las migrantes objeto del delito de tráfico de migrantes no deben de ser sometidos a enjuiciamientos penales. Los migrantes son víctimas que necesitan protección. Por lo tanto, se hace hincapié en la penalización de los responsables del tráfico y de los grupos delictivos organizados que están tras ellos.

\subsection{Penalizar el tráfico de migrantes}

A fin de acelerar los procedimientos judiciales y de evitar la creación de refugios seguros para los traficantes, los Estados miembros quedan obligados en virtud del Protocolo a promulgar leyes nacionales que tipifiquen como delito penal el tráfico de migrantes, incluidos los siguientes delitos:

a. La facilitación, el suministro o la posesión de documentos de viaje o de identidad falsos;

b. La utilización, la posesión o la presentación de documentos falsos para introducir migrantes clandestinamente;

c. La organización o dirección de otras personas para que utilicen, posean o presenten documentos falsos, o la participación como cómplice en dichos actos (Artículo 6).

En consonancia con la idea de penalizar únicamente a los traficantes, este protocolo establece que las víctimas, los familiares y las instituciones que puedan ofrecer albergue por motivos humanitarios no están sujetos a enjuiciamiento penal con arreglo al Protocolo. Asimismo, establece que la repatriación de los migrantes objeto de tráfico ilícito debe efectuarse en forma expedita, de manera ordenada y teniendo debidamente en cuenta la seguridad de la persona.

\subsection{Tráfico de migrantes por mar}

El tráfico por mar no sólo es peligroso para los migrantes, sino que también es un asunto jurídico muy complejo para las autoridades, porque los delitos cometidos en el mar son materia del Derecho Internacional. Si bien el tráfico de mercaderías ilícitas como drogas, cigarrillos y armas, se aborda en acuerdos internacionales, la trata de personas por mar y el tratamiento de las víctimas es un aspecto que todavía no se ha reglamentado. Por ello se incluyó en el Protocolo un conjunto de cláusulas independientes para combatir el tráfico de migrantes por mar. 
El Protocolo para prevenir, reprimir y sancionar la trata de personas, especialmente mujeres y niños, define el delito de trata como:

Por trata de persona se entiende la captación, el transporte, el traslado, la acogida o la recepción de personas, recurriendo a la amenaza o al uso de la fuerza u otras formas de coacción, el rapto, el fraude, al engaño al abuso de poder o de una situación de vulnerabilidad o a la concesión o recepción de pagos o beneficios para obtener el consentimiento de una persona que tenga autoridad sobre otra, con fines de explotación.

Este instrumento jurídico internacional tiene como fines: prevenir y combatir la trata de personas, prestando especial atención a las mujeres y niños, proteger y ayudar a las víctimas de dicha trata, respetando plenamente sus derechos humanos, y promover la cooperación entre los Estados Parte para perseguir y enjuiciar a sus responsables así como proteger a sus víctimas. A pesar de no ser un instrumento dirigido a promover la cooperación policial y judicial transfronteriza para luchar contra un delito, el Protocolo tiene en cuenta una dimensión de derechos humanos que es imprescindible para una protección efectiva de las víctimas de trata de personas (CIDEHUM, 2003:40).

Todo Estado Parte de este instrumento internacional deberá adoptar las medidas legislativas que sean necesarias para tipificar como delito en su Derecho Interno, tanto la trata de personas como el intento de cometer este delito, la participación como cómplice y la organización o dirección de otras personas para llevar a cabo la trata de personas. Belice, Canadá, Costa Rica, El Salvador, Guatemala, México, Nicaragua y Panamá, han ratificado este instrumento.

Cuadro 1. Relación entre la trata y el tráfico

\begin{tabular}{ll}
\hline Trata de Personas & Tráfico de Migrantes \\
\hline $\begin{array}{l}\text { Los desplazamientos pueden ser legales o } \\
\text { ilegales. }\end{array}$ & Pueden utilizarse o no documentos falsos. \\
& $\begin{array}{l}\text { Implica un cruce irregular de fronteras, los desplaza- } \\
\text { Se utilizan documentos originales o falsos. }\end{array}$ \\
mientos pueden ser por lugares no autorizados.
\end{tabular}

La persona tratante busca ganar dinero o algún otro beneficio a través del traslado de una persona con fines de explotación.

Se obliga o engaña a la víctima, no hay consentimiento.

Se restringe o limita el movimiento de la víctima con el fin de someterla a la explotación.

El bien comercial es la persona.

Se comete un delito contra la persona víctima de trata.
La persona traficante busca ganar dinero o algún otro beneficio posibilitando que una persona cruce la frontera sin los documentos y procedimientos requeridos por ley.

El traslado es voluntario, hay consentimiento de la víctima.

No hay restricción de movimientos (en la mayoría de los casos el tráfico termina al cruzar la frontera).

El bien comercial es el servicio de cruce de frontera.

Se comete un delito contra el Estado. El bien jurídico protegido es la soberanía del Estado. 
El delito de trata de personas y el tráfico ilícito de migrantes se interrelacionan cuando los tratantes de personas se sirven de las redes del tráfico ilícito de migrantes para captar a las víctimas de la trata. El migrante que paga al "coyote" o "pollero" para pasar una frontera a menudo queda desprotegido al otro lado y es presa fácil de redes de tratantes. Los tratantes, a través de reclutadores ilegales, hacen que las familias de las víctimas paguen un insumo para que sus hijos e hijas salgan del país. Estas personas están convencidas de que sus familiares van a trabajar, en la mayoría de los casos como empleadas domésticas, como profesores de español, trabajadoras en sodas, restaurantes, o vendiendo joyas. Al final, esas personas son conducidas por los tratantes a los países de destino para trabajar forzadamente en la industria del sexo, en trabajos esclavizantes o extracción de órganos. En su mayoría, estas personas son mujeres o menores de edad (CIDEHUM, 2003:14).

\subsection{La Convención del $90^{3}$ y el tráfico ilícito de migrantes}

El objetivo esencial de la Convención del 90 es que todos los trabajadores migratorios y sus familiares puedan gozar de sus derechos humanos independientemente de su situación jurídica. Este instrumento incorpora un estándar mínimo de derechos que serán respetados y garantizados por los Estados Parte a todos los trabajadores migrantes y sus familias que estén bajo su jurisdicción, incluso en el supuesto de que éstos residan y trabajen en el Estado Receptor de forma irregular (González, 2005:37).

La Convención del 90 no impone restricción alguna a las condiciones que utilizan los Estados Parte para la admisión de los migrantes. Este instrumento internacional respalda el ejercicio y defensa de la soberanía de cada Estado para resguardar el territorio nacional, lo cual es legítimo y legal, siempre y cuando impere el respeto de los derechos humanos de quienes están sujetos a los regímenes migratorios.

\subsection{La OIT y el tráfico ilícito de migrantes}

La Convención No. 143 sobre Trabajadores Migrantes de 1949 (Cláusulas suplementarias), impone la obligación general de respetar los derechos humanos fundamentales de todos los trabajadores migrantes en el empleo y de adoptar las medidas necesarias para detectar y suprimir las migraciones clandestinas y el empleo ilegal de migrantes. También obliga a los Estados Parte a fomentar una auténtica igualdad de trato a los migrantes en lo que se refiere a empleo y ocupación, seguridad social, derechos sindicales y culturales, y libertades individuales y colectivas. La Recomendación 151 complementa este convenio.

\section{Derecho Interno}

\subsection{Trata de personas}

El delito de trata somete a la persona objeto de dicho ilícito a una situación de esclavitud sexual o laboral según sea el fin de la trata. Sin embargo, a pesar de que constitucionalmente está prohibida la esclavitud en todas sus formas (Arto. 40 Constitución Política de Nicaragua), en la práctica persisten casos de trata y además no se cuenta con una tipificación de este delito en la legislación penal vigente. 
Según el Código Penal, comete delito de trata el que recluta o engancha a personas con o sin consentimiento, bajo amenaza, ofrecimientos, engaños, cualquier otro semejante, para ejercer la prostitución dentro o fuera del país, o las introduzca al país. La pena que se aplica es de 4 a 10 años - la máxima - cuando la víctima es menor o existe unión de hecho estable. Además, el Código Penal vigente distingue entre trata y trata de blancas. Para este último delito establece que: "Comete delito de trata de blancas, el que se dedique al tráfico internacional de mujeres o niños destinados a la prostitución o comercio carnal y sufrirá la pena de presidio de 3 a 5 años" (Arto. 552 Pn.). En esta disposición, se refiere como sujetos pasivos del delito a mujeres y niños. El fin de la trata de blanca es exclusivamente la explotación sexual y debe darse fuera del territorio nacional. Excluye la explotación laboral y la explotación sexual de los niños, niñas y adolescentes dentro del territorio. Por otro lado, la Ley 287, Código de la Niñez y la Adolescencia, prohíbe a las agencias de publicidad y medios de comunicación social cualquier acto que promueva la prostitución y pornografía infantil (Arto. 67).

La tipificación y sanción de este delito es insuficiente, no se adecua a los estándares internacionales, no garantiza protección a la víctima y no comprende todos los supuestos de este ilícito. A pesar de esto, a propuesta de organizaciones de la sociedad civil, el Proyecto del nuevo Código Penal establecerá cinco figuras para tipificar delitos, tales como: actos sexuales con personas menores de edad mediante pago; corrupción sexual de personas menores de 18 años; pornografía con personas menores de 18 años; promoción del turismo con fines de explotación sexual y trata de personas con fines sexuales; el tráfico de personas con fines de explotación laboral y participación forzada en conflictos armados; y el tráfico de órganos humanos. ${ }^{4}$

A nivel regional, con apoyo de la OIM, cada país ha elaborado protocolos de procedimientos para la repatriación de niños, niñas y adolescentes víctimas de trata. Nicaragua ha firmado su protocolo y actualmente se encuentra en la fase de diagramación de los procedimientos.

\subsection{Ley 240-513, Ley de Control del Tráfico de Migrantes Ilegales}

Nicaragua es un país principalmente emisor de población migrante (hacia Costa Rica y Estados Unidos), pero a la vez, como todo el resto de la región centroamericana, es un país de tránsito hacia Estados Unidos. Particularmente, en Nicaragua está vigente la Ley 240513, Ley de Control del Tráfico de Migrantes Ilegales (de carácter penal)5. Esta Ley, en conjunto con algunas disposiciones del Código Penal vigente referidas a la documentación fraudulenta y las leyes de Migración y Extranjería (1993), conforman el marco jurídico que controla y regula el fenómeno de la migración irregular. Este marco normativo está ceñido por una política migratoria de carácter restrictivo que se centra en el control de la frontera, en la detención del inmigrante indocumentado y en su expulsión.

La Ley 240 tiene por objeto regular, controlar y sancionar a quienes realicen tráfico ilegal de personas por el territorio nacional. De conformidad con dicha Ley, el traficante o el "coyote" es quien debe ser sancionado por cometer el ilícito de tráfico. Pero al momento de aplicarse la normativa, quien termina siendo sancionado es el migrante irregular y en la mayoría de los casos el traficante queda impune. 


\section{Tipificación del delito de tráfico de migrantes:}

El tráfico de migrantes es tipificado por la Ley 240 como un delito donde el bien jurídico protegido es la soberanía del territorio nicaragüense. La Ley 240 define este delito como: "el ingreso y traslado de extranjeros en el territorio nacional sin llenar los requisitos de Ley” (Arto. 7). De acuerdo con esta norma, el ingreso de extranjeros por intermedio de otras personas puede tener por objeto trasladarse a otro país o radicarse en el territorio nacional.

Según la Ley 240 (Arto. 19) cometen delito de tráfico de migrantes ilegales las personas naturales que, con ánimo de lucro, ejecuten o se dediquen a todas las actividades para hacer ingresar o salir a nacionales o extranjeros de forma ilegal del territorio nacional con objeto de radicarlos dentro de Nicaragua o pasarlos en tránsito a terceros países valiéndose de los siguientes medios:

1) Sirviendo como guías a extranjeros para introducirlos al territorio nacional por lugares no habilitados como puestos fronterizos.

2) Ocultando a extranjeros en el interior de vehículos o cualquier otro medio de transporte para evitar el control migratorio.

3) Gestionando reposiciones de partidas de nacimiento, cédula de identificación ciudadana o pasaportes con datos falsos o utilizando los documentos de algún nicaragüense, o prestándolos o facilitándolos para cambiar la identidad de extranjeros.

4) Trasladando al extranjero dentro del territorio nacional u ocultándolo en cualquier lugar.

5) Las personas naturales señaladas en los artículos 14 (propietarios de hospedajes, pensiones, hoteles) y 15(empleadores que contraten a trabajadores extranjeros sin documentos $)^{6}$ cuando sean reincidentes.

6) Las personas señaladas en el artículo $13^{7}$ (empresas transportadoras) también cometen el delito de tráfico de migrantes ilegales.

\section{Reforma a la Ley 240: Ley 240-513}

En 2005 algunas de las disposiciones de esta Ley fueron reformadas. Organizaciones de la sociedad civil denunciaron que la Ley 240 criminalizaba al migrante extranjero. La Red Nicaragüense de la Sociedad Civil para las Migraciones pidió a la Asamblea Nacional la reforma total de la Ley de Control de Tráfico de Migrantes Ilegales, fundamentando que viola los derechos humanos de los ciudadanos extranjeros que ingresan de forma irregular al país. La Dirección General de Migración y Extranjería (DGME) también presentó una propuesta de reforma a esta Ley en la que se planteaba la necesidad de asignar presupuesto para la repatriación de los migrantes irregulares y así respetar el tiempo de detención previsto en la normativa. Finalmente, la Asamblea Nacional reformó la Ley 240 mediante el Decreto 513. ${ }^{8}$

Las Reformas a la Ley 240-513 humanizan el trato al migrante irregular. El migrante ya no enfrentará (sólo si es reincidente) un juicio y una sanción de tres meses de cárcel inconmutables por tener un status migratorio irregular. Se establece un período de 
retención por un plazo de 48 horas para preparar la deportación. Sin embargo, este plazo no se respeta sobre todo por la falta de recursos económicos del migrante para asumir el costo del pasaje de regreso a su país. El Centro de Retención Migratoria (CRM) no cuenta con el presupuesto suficiente para agilizar el proceso de deportación. En consecuencia muchos migrantes permanecen retenidos más tiempo del establecido por las reformas a la Ley.

Al tipificar el tráfico ilícito de migrantes, la reforma a la Ley 240 hace distinción entre autores intelectuales y materiales. Los autores intelectuales y materiales del delito del tráfico de migrantes serán sancionados con penas de cinco a diez años de privación de libertad y una multa que oscilará entre 35 y 100 salarios mínimos promedio, más el decomiso de los bienes muebles e inmuebles incautados y utilizados para la comisión del delito. Estas reformas reducen además las penas de los cómplices.

Las reformas a la Ley 240 reconocen el derecho a solicitar un status migratorio a aquel extranjero unido en matrimonio o en unión de hecho estable con un nacional. Antes de la reforma, el matrimonio de un inmigrante ilegal con un ciudadano/a nicaragüense no le otorgaba derecho inmediato de solicitar ningún status migratorio en el territorio nacional ante las autoridades competentes.

\subsection{Política migratoria con carácter restrictivo: el visado}

La aprobación y aplicación de normas que estipulen requisitos migratorios cada vez más estrictos y rigurosos se ha convertido en uno de los mecanismos principales para implementar las políticas migratorias. Éstas no consiguen frenar los flujos migratorios, sino que desincentivan la migración documentada y obligan a la población migrante a cruzar las fronteras evadiendo los controles. Este efecto es mayor en aquellos migrantes cuya nacionalidad está clasificada como restringida y necesitan tramitar una visa para poder entrar a un país determinado.

Las políticas migratorias en Centroamérica han seguido esta línea bajo la influencia de las políticas estadounidense en respuesta a los flujos migratorios con destino hacia ese país. En las últimas décadas, el perfil de la inmigración en Estados Unidos ha cambiado profundamente, mientras que en 1960 más del 75\% de los inmigrantes procedía de Europa, en la actualidad, esta cifra se ha reducido al 15\%. Más de la mitad de los inmigrantes en Estados Unidos son de América Latina. Cabe distinguir entre dos olas de inmigración latinoamericana bien diferenciadas: en los años sesenta emigró la elite cubana que huía de la revolución de Fidel Castro, y en los años ochenta y noventa se produjo la emigración económica proveniente de México, Centroamérica y el Caribe. Con 39,9 millones de hispanos, Estados Unidos concentra la comunidad hispana más importante del mundo (Real Instituto Elcano, 2005).

Desde 1996, y fundamentalmente después de los atentados del 11 de septiembre de 2001, la política de inmigración estadounidense se ha caracterizado por el endurecimiento de los procedimientos contra los inmigrantes ilegales - mayoritariamente procedentes de México, El Salvador y Guatemala - y la puesta en práctica de controles fronterizos más estrictos. Estos controles han tenido repercusiones directas en la acogida de refugiados políticos: bajo 
la Administración Bush, su número se ha reducido en un 19\% entre 1999 y 2001 y en 2002 se encontraba en su nivel más bajo desde 1987. Del mismo modo, la cuota de nacionalización también se redujo en un 6\% entre 2001 y 2002 (Real Instituto Elcano, 2005). En esta misma dirección, en 2005 se aprobó en Estados Unidos la Ley para la Protección Fronteriza, Antiterrorismo y Control de Inmigración Ilegal.

El desarrollo de las políticas migratorias estadounidense ha influido en el diseño de las políticas migratorias y en las legislaciones de los países de la región centroamericana, dado que ésta sirve de tránsito para la inmigración con rumbo norte. En Nicaragua está vigente el Decreto $\mathrm{N}^{0} 57-2005^{9}$ que regula todo lo concerniente a la exención y obligatoriedad de visa de ingreso al territorio nicaragüense (Arto. 1). Para determinar la exención y la obligatoriedad, este Decreto establece tres categorías:

Categoría “A” Exento de visa,

Categoría "B” Consular o sin consulta y

Categoría “C” Consultada.

Estas categorías de visa A, B y C se otorgan para establecer las exenciones u obligatoriedad de visa según el tipo de documento de viaje y el origen. En este sentido, estas categorías son distinciones discriminatorias ya que la obligación o exención de portar visa está dada según el lugar de origen, restringiendo de esta manera la libertad de movilidad por razones de nacionalidad o pertenencia a un Estado determinado. Lo cierto es que la distinción de los países según las categorías A, B, C, obedecen a los intereses geopolíticos de Estados Unidos, que ha impuesto en la región centroamericana políticas migratorias con carácter restrictivo para frenar el flujo de migrantes hacia Norteamérica. ${ }^{10}$

\section{Acuerdos de Libre Visado}

El Decreto 57-2005 establece (Arto. 6) que los acuerdos de libre visado firmados por la República de Nicaragua mantienen su vigencia. Según los datos presentados por la DGME, al 2003 Nicaragua tenía acuerdos de libre visado al menos con 42 países. Por mencionar algunos: Alemania, Bélgica, Bulgaria, Belice, Costa Rica, Bolivia, Cuba (Diplomático o Misiones oficiales) Chile, República Dominicana (Diplomático, Oficial y de Servicio), y República Oriental del Uruguay. ${ }^{11}$

\section{Tráfico Ilícito de Migrantes en la Frontera de Peñas Blancas}

En el puesto fronterizo de Peñas Blancas existen dos flujos migratorios: los extranjeros que vienen de sur a norte, que son de nacionalidades suramericanas, asiáticas y africanas; y los nicaragüenses que van hacia Costa Rica. La primera modalidad de migración es declarada ilegal cuando el ingreso se da por puntos ciegos o por bordes fronterizos donde no hay controles migratorios ni policiales, o por el área internacional legal, pero con documentos alterados, falsificados, o cuando los funcionarios les permiten el ingreso. ${ }^{12}$ La segunda modalidad, que representa un flujo migratorio sur-sur (Nicaragua-Costa Rica) propio de las migraciones limítrofes, ${ }^{13}$ afecta fundamentalmente al territorio costarricense. Dentro de esta dinámica intraregional también tiene lugar la migración irregular o clandestina. 


\subsection{Flujo sur-sur: "viajamos con el pasaporte verde"}

Los nicaragüenses que emigran hacia Costa Rica de forma irregular lo hacen evadiendo los puestos fronterizos, ya sea por San Carlos o por Peñas Blancas. En la frontera de Peñas Blanca, en la zona de Cárdenas ${ }^{14}$, municipio de Rivas, existe un gran número de puntos ciegos que son utilizados como rutas de acceso al territorio costarricense por los traficantes, "coyotes" y los migrantes originarios de la zona fronteriza. De esta manera, los migrantes que no tienen los documentos adecuados para viajar, cruzan la frontera haciendo uso del servicio de paso de frontera que les proporcionan los "coyotes".

La migración ha sido una actividad económica histórica en Cárdenas. En la zona existe el comercio de las denominadas Polacas, personas que venden ropa y otros tipos de mercadería a ambos lados de la frontera. Algunas utilizan, como medio de transporte, barcos que navegan en el lago de Nicaragua y viajan a localidades de Costa Rica, otras utilizan buses. Aproximadamente mil personas oriundas de Cárdenas laboran en fincas fronterizas en territorio costarricense, dedicándose a labores de ganadería, corte de madera, naranjas, etc. (González y Pérez, 2005).

La regla general es que los que han emigrado lo han hecho utilizando el denominado "pasaporte verde" (ingresar por veredas en el monte) (González y Pérez, 2005). En la frontera de Peñas Blancas diario pasan 20 mil nicaragüenses de manera legal y otros 10 mil se escabullen por cualquiera de los puntos ciegos (Henríquez y Hernández, 2004). Esta situación facilita que la zona de Cárdenas sea un lugar de tránsito de migrantes, en donde circulan diariamente entre 50 y 80 personas que van buscando su ingreso de forma irregular a Costa Rica. En la frontera de Peñas Blancas es notoria la presencia de "coyotes", basta con tomar un autobús hasta la frontera, llevar una mochila al hombro, el deseo de cruzar la frontera, y en seguida aparece una o un "coyote" ofreciendo sus servicios.

La mayoría de los migrantes que circulan por Cárdenas son nicaragüenses, pero por el sector de Peñas Blancas circulan migrantes extraregionales (González y Pérez, 2005). Este colectivo de migrantes corresponde al flujo sur-norte.

\subsection{Flujo sur-norte: "en busca del sueño americano"}

La migración de tránsito sur-norte es una migración que involucra a toda la región centroamericana, razón por la cual se han aprobado y puesto en práctica en los países de la región, leyes homólogas a la Ley 240-513, sobre todo en los países que forman parte del CA-4. La regulación y control del fenómeno de migración clandestina por la región centroamericana tiene fundamento en la influencia de la política migratoria estadounidense, marcada por un enfoque de seguridad nacional en el que se persigue contener o detener este flujo de población migrante que aspira a llegar a los Estados Unidos.

El control que los países centroamericanos realizan de este flujo de migración clandestina obedece a intereses extraregionales y a la vez afecta el respeto de los derechos humanos de la población migrante, sobre todo cuando los controles son realizados de forma arbitraria a través de redadas efectuadas por las autoridades correspondientes o cuando la norma misma contiene disposiciones que sancionan severamente al migrante hasta el punto 
de criminalizarlo. De hecho, la mayoría del tiempo es el migrante el sancionado y no el traficante.

En el caso de Costa Rica, la Ley de Migración y Extranjería contempla el delito de tráfico ilícito de migrantes y lo tipifica como tráfico ilícito de personas. La pena que se impondrá será de dos a seis años de prisión a quien, con fines de tráfico ilícito, conduzca o transporte personas para su ingreso o egreso del país por lugares no habilitados por la DGME, evadiendo los controles migratorios establecidos o utilizando datos o documentos falsos, y a quien, con fines de tráfico ilícito de personas, aloje, oculte o encubra a extranjeros que ingresen o permanezcan ilegalmente en el país.

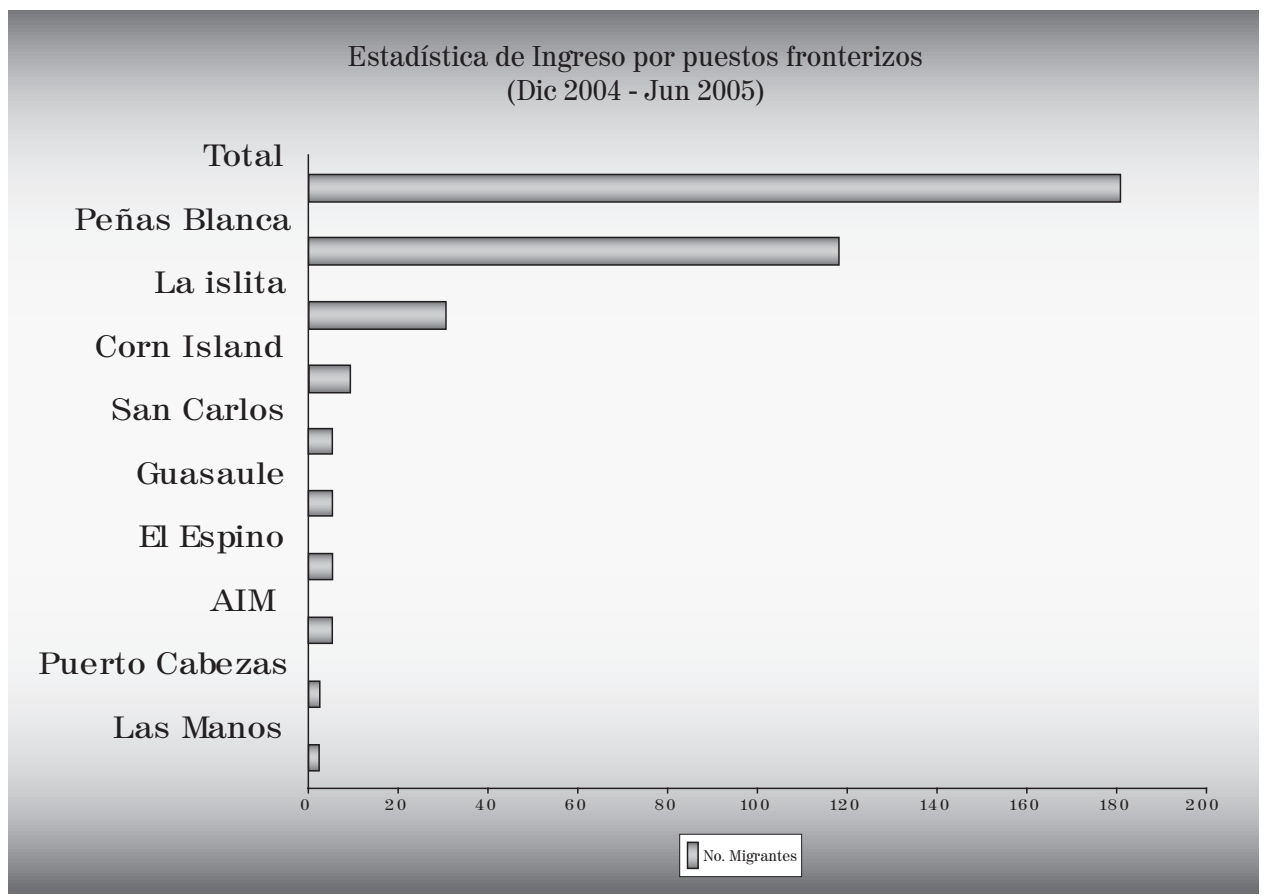

Ilustración 1. Estadísticas de ingreso por puestos fronterizos (diciembre 2004-junio 2005) Fuente: Elaboración propia en base a los registros del CRM en la DGME

El flujo sur-norte es alimentado principalmente por migrantes originarios de Suramérica. En menor medida transitan migrantes africanos y asiáticos. La región centroamericana sirve como zona de tránsito para estos colectivos de migrantes que se dirigen hacia el norte. Al territorio nicaragüense ingresan en gran medida por el puesto fronterizo de Peñas Blancas, a éste le sigue La islita y en tercer lugar está Corn Island. Por estos últimos puestos fronterizos suelen llegar en su mayoría migrantes colombianos.

La frontera de Peñas Blancas tiene una extensión de 309 kilómetros. En ésta existen varios puntos ciegos que son usados por los llamados "coyotes" para cruzar a los migrantes. En ocasiones el migrante acepta los servicios de los falsificadores de documentación, quienes 
pueden estar o no en coordinación con las redes de traficantes de migrantes. La Dirección de Migración y Extranjería de Peñas Blancas suele recibir ciudadanos/as costarricenses que cruzan la frontera sin documentación. Los migrantes cuya nacionalidad está catalogada como restringida (exigencia de visados) utilizan sellos falsos para ingresar al territorio nicaragüense. Al ingresar con estos sellos falsos al territorio nicaragüense, los migrantes son identificados por las autoridades e inmediatamente rechazados administrativamente. ${ }^{15}$

\subsection{EI CA-4}

Nicaragua, Honduras, El Salvador y Guatemala, por medio del CA-4, permiten que un adulto nacional permanezca en cualquiera de estos países por un período de 90 días, luego del cual necesita permiso para permanecer (Lamberg, 2002). El uso de la cédula de identidad como documento de viaje no sólo facilita el ingreso y la estadía en estos países, sino que también puede ser utilizada por un ciudadano extraregional para cruzar las fronteras de los países que utilizan el CA-4. Por ejemplo, un migrante cubano entró a territorio nicaragüense cruzando de forma clandestina la frontera de Peñas Blancas, adquirió una cédula de identidad ciudadana nicaragüense con la que salió del país hasta llegar a El Salvador, en donde fue descubierto por las autoridades migratorias y enviado al CRM en Managua. ${ }^{16}$

Por el momento, los países del Sistema de Integración Centroamericana han aprobado la creación de un pasaporte único centroamericano que permita tener un documento con un distintivo para todos y un número de registro que agilice el tránsito por esos países del istmo. Costa Rica se reserva la participación en esta propuesta por razones propias de su ordenamiento jurídico nacional (SICA, 2005).

\section{Aplicabilidad del marco normativo a la realidad del fenómeno del tráfico ilícito de migrantes}

De acuerdo con la Ley 240-513, la DGME es la depositaria de todo ciudadano que se encuentre en situación migratoria irregular dentro del territorio nicaragüense. Con la reforma a la Ley 240 el ingreso y/o permanencia ilegal en el territorio nacional sigue considerándose delito, aunque se eliminaron los tres meses de cárcel inconmutables a los migrantes irregulares. Sin embargo, si después de la deportación u repatriación del migrante a su país de origen éste intentare reingresar durante veinticuatro meses, contados a partir de la fecha de la deportación o repatriación, será sujeto a tres meses de privación de su libertad. Esta nueva disposición ha venido a mejorar la situación del migrante indocumentado, ya que éste no tiene que esperar a cumplir la condena de los tres meses de cárcel para ser devuelto a su país de origen. Incluso se aminora la situación de hacinamiento que a veces se da en el CRM. Sin embargo, esta reforma, favorable a los migrantes, no responde totalmente a las necesidades y dificultades que enfrentan los migrantes y las autoridades para hacerle frente a este fenómeno migratorio, ya que la normativa carece de aplicabilidad en relación a la dinámica del fenómeno.

Con las reformas al artículo 21 de la Ley 240, el extranjero ya no es detenido para ser procesado, sino que inmediatamente pasa a la orden de Migración e inicia el procedimiento administrativo de la deportación. En el caso del traficante, se iniciará un proceso penal por 
la comisión del delito de tráfico ilícito de migrantes. ${ }^{17}$ Sin embargo, como mucha normativa vigente en Nicaragua, la ley 240-513 carece de aplicabilidad porque la aprobación y/o reforma de la legislación no va acompañada de una reforma estructural que garantice su efectividad y que se adecue a la realidad económica, política y social del país.

Uno de los principales vacíos de la Ley es que carece de presupuesto para su total efectividad. No es posible cumplir el término de 48 horas que la Ley establece debido a que los migrantes no siempre tienen la facilidad económica para conseguir el boleto de viaje y regresar a su país. La Ley sólo establece la obligación de las aerolíneas de reservar, a favor del Estado de Nicaragua, un mínimo de dos cupos para los extranjeros que vayan a ser deportados, expulsados o repatriados a su país de origen. La disposición no garantiza el boleto en sí. Por esta razón, la DGME planteó dentro de las reformas la facilidad para obtener los boletos. La falta de recursos económicos para comprar los boletos en muchos casos provoca que el o la migrante que no tiene los recursos suficientes, sea retenido más de 48 horas (tres meses o más). En la mayoría de los casos los migrantes retenidos son jefes de familia - los que proveen los recursos al núcleo familiar - por lo que contar con el dinero para la repatriación resulta más difícil. Mientras los familiares de los migrantes envían el dinero para comprar el boleto de regreso de los migrantes, éstos permanecen en el CRM.

Otra de las limitaciones en la atención a los migrantes irregulares - en ocasiones además víctimas del tráfico ilícito de migrantes - es que el CRM no cuenta con una infraestructura adecuada, y cuando hay un flujo fuerte de migrantes retenidos, éstos tienen que estar hacinados. En parte esto se debe a la falta de presupuesto destinado para mejorar y/o crear un centro de retención con las condiciones materiales básicas para albergar a los migrantes. A esto se suma la poca presencia de organizaciones de la sociedad civil que den un verdadero acompañamiento a la población migrante.

A pesar de las limitaciones materiales y de presupuesto, los funcionarios de Extranjería brindan un trato humano a los inmigrantes retenido. Esto fue confirmado por los inmigrantes entrevistados en el CRM. Un grupo de inmigrantes peruanos, detenidos arbitrariamente y luego abandonados por autoridades de Honduras, decidieron volver a Nicaragua y presentarse a su consulado por la certeza de que el trato de las autoridades de Migración en Nicaragua sería el adecuado y no correrían ningún peligro.

\section{1. ¿A quien penaliza la Ley 240 ?}

El artículo 21 de la Ley 240 - antes de la reciente reforma - sancionaba al migrante con pena de tres meses de arresto inconmutable. Una vez cumplida la pena, la DGME debía proceder a la deportación a su país de origen. Con esta disposición no sólo se criminalizaba al migrante indocumentado, sino que éste sufría violación a sus derechos humanos y a las garantías del debido proceso.

Para los agentes de la Policía Nacional, las disposiciones de la Ley 240 eran un poco drásticas con el ciudadano extranjero. El migrante era sancionado, mientras que el traficante quedaba impune y ganándose el dinero sustraído al migrante. Los migrantes sufrían desmanes: primero la dificultad que tienen en su trayecto, sus papeles, la pérdida de sus cosas, las 
detenciones por las autoridades migratorias, y maltrato por "coyotes" y a veces por las autoridades policiales y migratorias. ${ }^{18}$

Según datos de la DGME (septiembre de 2004), de 1990 a 2003 han sido retenidos 5,624 extranjeros, de éstos, 2,113 eran peruanos, 563 ecuatorianos, 472 colombianos, 282 indios, 210 dominicanos, 123 costarricenses. En 1995 se registró el mayor número de detenidos con 880 y la menor cifra fue en 1990 con 72 personas detenidas. En el período de diciembre de 2004 a junio de 2005 fueron retenidos 181 extranjeros: 16 cubanos, 21 colombianos, 65 peruanos, 1 argentino, 4 salvadoreños, 56 ecuatorianos, 3 de República Popular de China, 2 guatemaltecos, 3 bolivianos, 3 estadounidenses, 1 dominicano, 3 costarricenses, 1 mexicano, 1 italiano y 1 español.

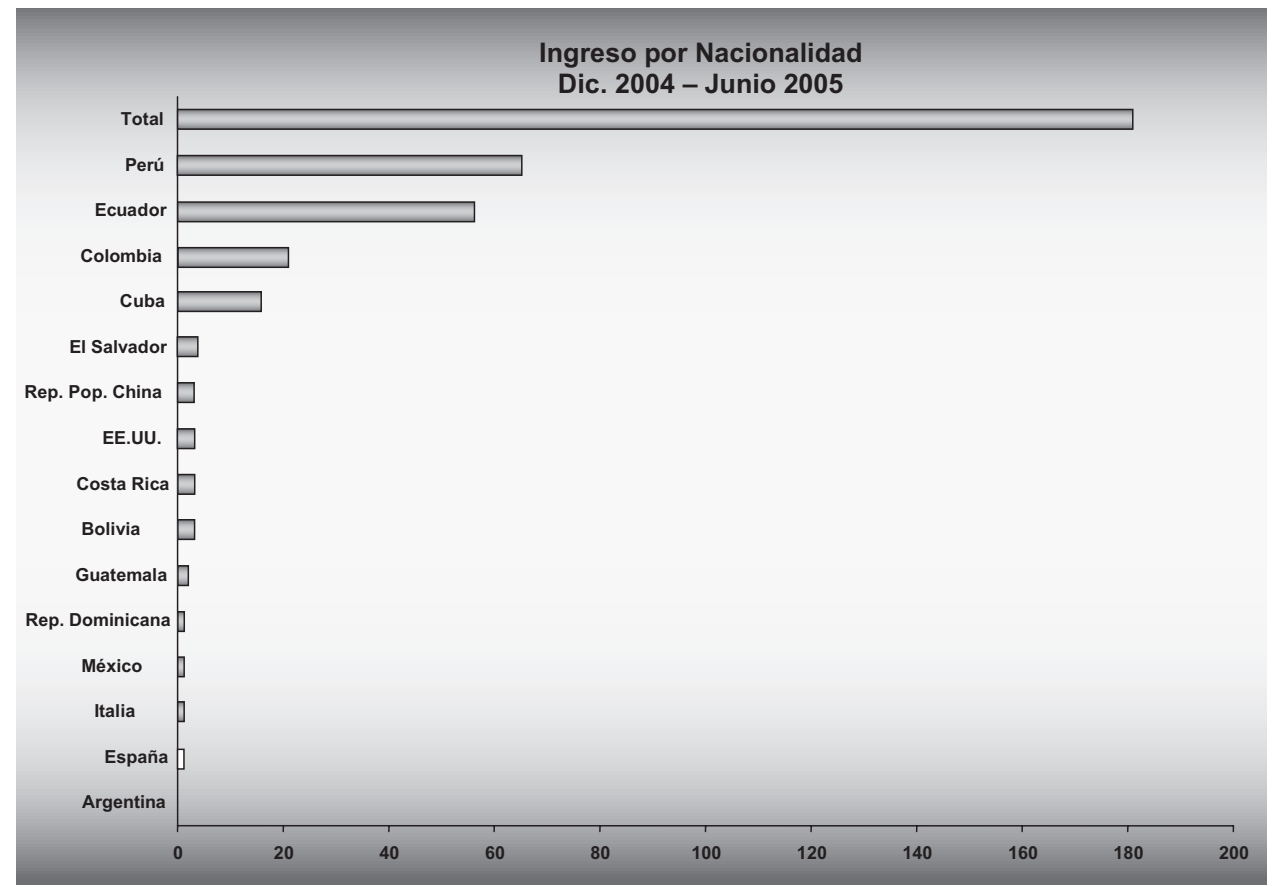

Ilustración 2. Ingreso por nacionalidad. Diciembre de 2004 a junio de 2005 Fuente: Elaboración propia en base a Registros del CRM de la DGME.

De acuerdo con el Decreto No. 57-2005 sobre el visado restringido, Bolivia, Colombia, República Dominicana, Ecuador, Perú y Costa Rica pertenecen a la Categoría B (visa consular), España, Italia, México, Argentina y Estados Unidos pertenecen a la Categoría A (exentos de visa), y en la Categoría $\boldsymbol{C}$, referida a los países que necesitan visa de ingreso consultada, se encuentran Cuba y República Popular de China. El Salvador y Guatemala se rigen por el SICA y por lo tanto no necesitan visa para movilizarse por territorio nacional, sólo deben de portar su CA-4. La mayoría de inmigrantes proviene de Suramérica, principalmente de Perú, Ecuador y Colombia, seguidos de Cuba. El principal punto de entrada de este colectivo fue la frontera de Peñas Blancas y el destino de estas poblaciones es Estados Unidos. 


\section{Traficantes de migrantes: "coyotes, polleros o seudo coyotes"}

El aspecto de la migración que se refiere al tráfico de migrantes es motivo particular de preocupación para la comunidad internacional. La noción de tráfico puede ser abordada desde diversas perspectivas. Según la Relatora Especial de Naciones Unidas para los derechos de los trabajadores migrantes, el tráfico ilícito de migrantes se distingue del "coyotaje" (smuggling). Mientras el tráfico incluye una organización compleja de contactos, el "coyotaje" se refiere exclusivamente a los servicios ilícitos de paso de frontera. ${ }^{19}$

En la frontera de Peñas Blancas existen entre 200 y 300 personas a cada lado de la frontera que se dedican al "coyotaje". Según los "coyotes" entrevistados, el surgimiento del "coyotaje" es simultáneo al surgimiento de los mismos flujos migratorios:

Yo empecé, cuando a través del Frente Sandinista ganó las elecciones que fue cuando la gente comenzó a emigrar. Es decir, a partir del 80. La gente se iba por razones políticas ahora se van para buscar trabajo.

La imagen de aprovechado y delincuente de la que "goza" el llamado "coyote" es en parte inexacta. El "coyote" está inserto en la vida de las comunidades fronterizas ubicadas a ambos lados de la línea, su presencia es esencial para las economías internas y ocupa un lugar preponderante en la dinámica social de las mismas (Kauffer, s.f.). Los "coyotes" que prestan sus servicios ilicitos de paso de fronteras en Peñas Blancas en su mayoría son originarios de Rivas. Ellos consideran que facilitar el paso de frontera a los migrantes es una forma de ganarse la vida honradamente. No lo ven como un delito, al contrario, lo perciben como una cuestión de solidaridad y colaboración:

Yo lo que pienso es que haya un poco de amplitud de trabajo porque lo que pasa es que aqui no hay trabajo, la poquita gente que trabaja pasa de la pesca, buscando leñita, entonces la gente se va pues, aunque no quieran venir aqui se van pues, aunque no quieran, tienen que buscar el pan de cada día par sus hijos..$^{20}$

Sin embargo, en esta zona fronteriza existen "coyotes" que cometen delitos como robos, secuestros y violaciones. Los "coyotes" originarios de la zona (frontera de Peñas Blancas) afirman que aquellos "coyotes" que vienen de otros lugares del país - sobre todo de la capital - son quienes comenten este tipo de delitos contra los inmigrantes. En algunos casos los traficantes engañan al migrante presentándole un panorama de la situación seguro y fácil: Creo que es culpa del coyote porque le muestra un panorama muy diferente. A mí me dijo usted de acá a la isla es hora y media, que va fueron seis horas en el mar. Hay mucha mentira, la mayoría de la gente viene engañada por el coyote. Ese es el problema. Él es el que maneja todo, pero no da la cara. Él manda, pero no da la cara. Él maneja todo y no da la cara, él es el que dice vaya por allá, él está a la sombra. Y eso está difícil.

\subsection{Especialización del "coyotaje”}

En la medida en que los flujos de migrantes se diversifican, el "servicio" de los llamados "coyotes" también se diversifica. Con base en la observación participativa realizada en la frontera de Peñas Blancas se logró identificar que hay "coyotes" que sólo y exclusivamente se dedican a pasar a nicaragüenses a Costa Rica, mientras otros se dedican a cruzar a 
inmigrantes extraregionales. Un "coyote" que fue entrevistado para este estudio explicó que él no pasa extranjeros porque considera que hacerlo es peligroso e inconveniente, y que quienes se dedican a cruzar extranjeros generalmente no son originarios de Rivas.

En la frontera de Peñas Blancas se da tanto el "coyotaje" - mero paso de frontera - como el tráfico ilícito de migrantes. Este último requiere de una red organizada. Ambos tipos de servicios operan para los dos flujos migratorios. En el caso del flujo con dirección sur-sur, los "coyotes" se valen de contactos en ambos lados de la frontera para prestar sus servicios. De igual manera, el migrante que se dirige hacia el norte utiliza el servicio de los "coyotes" para cruzar la frontera. En otros casos lo hacen por sí mismos, sin recurrir a los servicios del "coyote". Y existen casos en los que, desde su país de origen, han hecho los contactos para el cruce de las fronteras. Lo cierto es que a medida que el migrante se acerca a su destino, las redes de traficantes de migrantes se hacen más complejas e implican mayores costos, tanto económicos como humanos.

\subsection{Penalización del "coyotaje"}

La principal dificultad que enfrenta el Sistema de Administración de Justicia para establecer la culpabilidad de los traficantes de migrantes es la obtención de pruebas de convicción suficientes para demostrar su actuación delictiva. ${ }^{21}$ Para poder procesar a los llamados "coyotes" por el delito de tráfico ilícito de migrantes, según la Ley 240-513, es necesario que se compruebe el ánimo de lucro, de lo contrario, los judiciales determinan absolverlos o decretar el sobreseimiento provisional. En ocasiones son puestos en libertad por falta de una denuncia de la víctima del tráfico.

El migrante da su consentimiento para ser guiado por el traficante y cruzar la frontera. En la mayoría de los casos no denuncia al "coyote" y sin denuncia no se puede iniciar una investigación. La deficiencia de algunos judiciales al momento de aplicar las leyes también influye para que la mayoría de los involucrados en el tráfico de personas en Nicaragua queden en libertad sin ser castigados. En 2004 la justicia nicaragüense conoció de unos 25 casos relacionados a la trata y al tráfico de personas, pero sólo uno de 19 involucrados fue objeto de condena. Pero esto no sólo se debe a la deficiencia que sufre el Poder Judicial en sus funciones, sino a la falta de una normativa penal que tipifique con claridad los delitos de tráfico ilícito de migrantes y trata de personas. El Código Penal vigente sólo contempla dos disposiciones que se refieren superficialmente a la trata de personas, cuando debería de tener un capítulo entero dedicado a tipificar estos delitos.

\section{¿Por qué los “coyotes” no son denunciados?}

Los migrantes que han usado los "servicios" brindados por los traficantes de migrantes y han sido defraudados por éstos - ya sea porque no lograron llegar a su destino y fueron capturados, perdiendo el dinero invertido y otros bienes, o fueron víctima de otros abusos - no siempre denuncian los hechos. Esta situación obedece a diversos factores:

- Los "coyotes" no dan un nombre verdadero. Los "coyotes" que fueron entrevistados para este estudio usan seudónimos. En algunas ocasiones citan al migrante en un 
parque.

- Los migrantes no denuncian al "coyote" porque no consideran que se esté cometiendo un delito contra ellos. Algunos migrantes y familiares de migrantes no denuncian al traficante por consideración al mismo "coyote". Incluso, es posible que no descarten la posibilidad de que en el futuro algún familiar se dedique a realizar esta actividad ilícita, entonces prefieren no iniciar ninguna acción penal. Esto no se puede generalizar, pero tampoco se puede obviar que la actividad ilícita del "coyotaje” también responde a la falta de empleo y salarios dignos para la población.

- Los traficantes de migrantes no son denunciados porque la familia o el mismo migrante no tiene la forma de comprobar que en efecto el "coyote" recibió dinero por prestar el "servicio" de guiar y hacer cruzar al migrante la frontera evadiendo los puestos de control migratorio.

- Cuando el migrante es detenido por las autoridades, la primera necesidad que surge es cómo arreglar su situación migratoria o regresar al país de origen; no es una prioridad para él/ella denunciar al "coyote".

La identificación del traficante o "coyote" es una tarea pendiente para las autoridades migratorias y policiales. En ocasiones no tienen la experticia para detectar y distinguir entre los "coyotes" y migrantes o entre los traficantes y traficados:

Uno es el traficado y el traficante. Por lo general existe una unión, una simbiosis. Siempre se rehúsan en reconocer o denunciar a los traficantes porque de una u otra forma ellos tienen un beneficio mercantil para tener su objetivo. Entonces es muy difícil tener muchos datos sobre los traficantes, además son personas que todo el tiempo andan con seudónimos, andan por la noche, con pasamontañas para no reconocerlos y a su vez estos mismos maltratan a los traficados, es decir al migrante. ${ }^{22}$

\section{Modus operandi}

En cuanto al modo de operar y de captar a migrantes se puede decir que quienes se dedican al "coyotaje" con larga trayectoria en este campo, tienen sus clientes establecidos, que les sirven de redes para captar más "clientela". Algunos migrantes contactan al "coyote" previamente, ya sea porque algún conocido se los recomendó o porque ellos lo conocen personalmente. Este es el caso de una profesora que emigró a Costa Rica guiada por uno de sus ex estudiantes que actualmente se dedica a trabajar en la frontera como "coyote". En general, al bajar del bus en la frontera de Peñas Blancas, el migrante encuentra a muchos "coyotes" - tanto hombres como mujeres - que le ofrecen sus servicios.

\section{Redes de traficantes}

Cuando el tráfico ilícito de migrantes va más allá del simple "coyotaje" o paso de frontera, estamos posiblemente frente a una red de tráfico ilícito de migrantes con contactos en los distintos países de tránsito que, a través de agencias de viajes o anuncios en periódicos, contactan a sus clientes. Existe una red de traficantes de indocumentados que se extiende desde Perú, Ecuador, Colombia y Centroamérica. Esta red tiene, en cada uno de estos países, miembros que contribuyen y que trabajan para hacer más fácil el tráfico ilícito de personas. 
Las redes del "coyotaje” pueden ser de diferentes niveles según la coordinación o el número de contactos que puedan tener y el lugar que tengan como destino para llevar la "mercancía". La migración de los nicaragüenses hacia Costa Rica (flujo sur-sur) es una migración transfronteriza que no requiere necesariamente de una red de traficantes muy organizada y obedece más a lo que la Relatoría de los Derechos Humanos de los Trabajadores Migrantes denomina como "coyotaje" o simple paso de frontera. Sin embargo, no se puede negar que existe una organización definida de estos "coyotes" en la frontera de Peñas Blancas. Uno de los "coyotes" entrevistados (originario de Managua) señaló que trabaja en coordinación con transportistas costarricenses e incluso suele coordinarse con algunas empresas de transporte turístico y funcionarios de migración costarricenses, a quienes paga cierta cantidad de dinero para conseguir el paso.

\section{El tráfico ilícito de migrantes y las redes del narcotráfico}

Los migrantes que han tenido la experiencia de cruzar con "coyotes" afirman que funcionan como una red porque todos se conocen y están coordinados unos con otros: "Ellos tienen contactos en todos lados. Son los mismos, yo he escuchado los nombres (seudónimos) y en otros lugares los repiten”. ${ }^{23}$ Las redes del tráfico ilícito de migrantes suelen ser vinculadas con el crimen organizado, sobre todo con el narcotráfico. Según el Jefe del CRM de Managua, este vínculo existe cuando una zona geográfica utilizada para el narcotráfico se convierte en algún momento dado en ruta para inmigrantes. En el caso de Nicaragua, esto sucede en la zona de la Costa Caribe: Bluefields, Corn Island y Puerto Cabezas. Se especula que en esta zona hay movimientos de tráfico de armas y de drogas, y los traficantes aprovechan las oportunidades que se les presentan para traficar con inmigrantes indocumentados.

El Jefe del CRM ha apuntado que entre los inmigrantes retenidos varios han expresado que al ser montados en pangas para llegar al territorio nicaragüense, han visto todo tipo de objetos en la pequeña embarcación. Hoy en día, la actividad del tráfico de drogas y armas se ha especializado y el tráfico de migrantes es un negocio más de estas redes de traficantes. ${ }^{24}$ En Nicaragua, por cada tres expendios que se cierran, se abren cinco, y se ha convertido en noticia frecuente hablar de avionetas con drogas. La Costa Caribe, dada su situación económica, social y política, y sobre todo su posición geográfica, se ha convertido en una de las zonas víctima del narcotráfico. ${ }^{25}$

La línea que separa a un traficante de inmigrantes de las redes del narcotráfico no es del todo visible. Para el Director de Extranjería, el "coyotaje” forma parte de una red que puede estar vinculada con el crimen organizado:

Lo que pasa es que esto es una red y lo que hemos dicho con otras autoridades como la Policía, es que la misma red trafica drogas, trafica personas, trata personas que es diferente, es decir ha diversificado su actuar, ya no sólo es droga sino que ellos mismos, la misma red ha diversificado su actuar, trata y también trafica.

En entrevista realizada al Sub-Comisionado de la Policía Nacional en Peñas Blancas, éste relató un caso en el que un "coyote” terminó involucrándose en el negocio del tráfico ilícito de estupefacientes:

[...] en Rivas hace tiempo había un famoso coyote que le decían el músico [...]. Él 
hizo mucho dinero, empezó con personas, pasaba peruanos y de otras nacionalidades. Después de que surgió la Ley y surgieron nuevos coyotes, empezó a pasar drogas. Ahora él está sancionado por drogas. Está en el Sistema Penitenciario porque la Ley que lo trata como coyote fue un poco flexible para él. Pero él no cayó como coyote, pero su actividad empezó así como coyote. Él conocía rutas, se movilizaba desde la frontera sur hasta el Guasaule y él comenzaba a hacer los contactos desde Panamá, Costa Rica - tenía casa donde escondía gente, etc. Este mismo sistema que usaba para los migrantes lo transformó para pasar drogas. Ahi es donde se combinan estas acciones y se unen a veces. ${ }^{26}$

\section{7. ¿Por qué viajar con "pasaporte verde"?}

Las razones que motivan a una persona a emigrar de forma clandestina o irregular se fundamentan en las mismas políticas migratorias restrictivas que cierran las fronteras, tanto con las mallas o muros construidas para evitar el ingreso, como con el conjunto de normativas que establecen una serie de procedimientos migratorios administrativos y burocráticos que tienen un costo económico que el migrante, en la mayoría de los casos, no puede asumir.

En el caso de la emigración de los y las nicaragüenses a Costa Rica se suma el hecho de que poseen una nacionalidad restringida en ese país, por lo que el ciudadano/a que desee ingresar en territorio costarricense requiere de una visa que tiene un valor de veinte dólares americanos. También hay migrantes extraregionales que tienen restricciones migratorias para ingresar a Nicaragua (categorías de países B y C).

La migración indocumentada de nicaragüenses también se debe al alto costo y trabas burocráticas para obtener los documentos de viaje adecuados (pasaporte, cédula de identidad o salvoconducto). En Nicaragua existe un déficit en las oficinas del Registro Civil y doble asiento de inscripción de los nacimientos. Sin partida de nacimiento no se puede solicitar cédula de identidad y sin ésta no se puede tramitar el pasaporte, y por tanto, la regularización en el país de destino está limitada por la deficiencia del aparato estatal del país de origen de proveer a sus ciudadanos de la documentación. La Red Nicaragüense de la Sociedad Civil para las Migraciones ha realizado una campaña de sensibilización e incidencia que promueve y demanda la migración documentada. El Comité Pro Cédula en el Exterior ha demandado la cedulación de los nicaragüenses en el exterior. Sin embargo, este tema se ha politizado y no hay voluntad política por proveer el derecho humano a la documentación de nuestros connacionales en el exterior.

\section{Costos y consecuencias de emigrar de forma clandestina o irregular}

El costo que el migrante paga por cruzar la frontera no sólo se reduce a lo económico, muchos son víctima de los mismos "coyotes" o de delincuentes que cometen asaltos, secuestros o violaciones en el trayecto.

Las consecuencias de emigrar de forma irregular no se reducen solamente a las sanciones administrativas a las que pueda estar sujeto el o la migrante que ingresa de forma irregular 
a un territorio extranjero. Esta irregularidad migratoria implica un estado de inseguridad jurídica que no permite la satisfacción de las necesidades básicas al no contar con un documento idóneo para demandarlas, mucho menos la obtención de beneficios que el Estado de acogida debe brindar a las personas de nacionalidad extranjera que ostenten una condición estable y permanente en el país.

\section{Tráfico ilegal de migrantes, trata de personas y derechos humanos}

Las personas migrantes enfrentan una variedad de obstáculos durante el proceso migratorio que ponen en riesgo el respeto de sus derechos humanos y hasta su vida. Estos riesgos aumentan por la existencia de redes que se dedican a traficar y tratar con las personas migrantes. Los derechos humanos frecuentemente vulnerados en el momento de la detención son principalmente: el derecho a la comunicación con el consulado respectivo o con los familiares, ${ }^{27}$ el derecho de protección contra la detención ilegal y arbitraria, ${ }^{28}$ el derecho a contar con asistencia jurídica gratuita y las garantías procesales. En deportaciones masivas en ocasiones se vulnera la integridad física de la persona migrante.

La Opinión Consultiva OC-18/03 de la Corte Interamericana de Derechos Humanos consolida el derecho al debido proceso legal como una garantía mínima que se debe brindar a todo migrante independientemente de su status migratorio. El amplio alcance de la intangibilidad del debido proceso comprende todas las materias y todas las personas sin discriminación alguna. La calidad migratoria de una persona no puede convertirse en justificación para privarla del goce y ejercicio de sus derechos humanos, en este caso el derecho a un debido proceso (González, 2005:37).

La libre circulación de personas es un derecho fundamental particularmente importante para los trabajadores migrantes y sus familias. La Convención de las Naciones Unidas para la Protección de los Derechos Humanos de los Trabajadores Migrantes y sus Familiares (1990) reconoce una gama de derechos a los migrantes y a sus familiares independientemente de su status migratorio y durante todo el proceso migratorio. Consagra el derecho a la protección efectiva contra toda violencia, daño corporal, amenaza o intimidación por parte de funcionarios públicos o particulares, grupos o instituciones.

En Nicaragua los principales lugares de origen de las víctimas de trata son los departamentos fronterizos de Nueva Segovia, Madriz, Chinandega y Managua, siendo su destino mayoritario Guatemala y en menor medida El Salvador (Mendoza López, 2004). En muchos casos la mayoría de las víctimas ha salido de Nicaragua de forma irregular. Los casos detectados en el país se encuentran en las coordenadas del flujo sur-norte y en el caso del tráfico ilícito de migrantes hacia Costa Rica la dirección de los flujos es sur-sur. Pero en la frontera de Peñas Blancas, los tratantes de personas pueden también encontrar posibles víctimas en el flujo sur-sur.

En la frontera de Peñas Blancas se ha constatado que adolescentes son víctima de la prostitución infantil. Para combatirla, la Casa de la Mujer en Rivas, con apoyo de las autoridades de la frontera de Peñas Blancas, realiza esfuerzos por sensibilizar a la población sobre el tema, incluyendo a los “coyotes”. Por su parte, la OIM, en coordinación 
con contrapartes locales, ha iniciado un proyecto piloto de atención y reinserción de víctimas de trata en Chinandega.

\section{La frontera: el punto de vistas de los actores}

Las fronteras son las líneas que se trazan en los confines de un país y que lo separan del o de los países vecinos, delimitando así el territorio en el que se puede ejercer la soberanía de cada cual. Cada país tiene la autoridad de exigir a las demás naciones que no invadan su territorio (siempre demarcado por fronteras), es decir, que se abstengan de actuar y penetrar en él. Según el Derecho Internacional, la soberanía es un concepto clave referido al derecho de un Estado de ejercer sus poderes. Estos poderes incluyen la potestad de cada Estado de establecer políticas migratorias que regulen y controlen las migraciones hacia y desde su país. Actualmente, las políticas migratorias son elaboradas mediante leyes que tienen como objetivo restringir el paso de los migrantes. Estas políticas implican normas migratorias con enfoques de seguridad nacional, así como la construcción de muros o mallas en las zonas fronterizas que van adquiriendo mayor popularidad entre los gobiernos. ${ }^{29}$

A través de sus políticas, los gobiernos cierran cada vez más sus fronteras a las personas y las abren para los bienes y el capital, aprovechando la situación de los inmigrantes que venden a un bajo costo su mano de obra en busca de mejores oportunidades. La coordinación y cooperación entre los Estados en materia migratoria es más difícil de conseguir, sobre todo cuando la única respuesta es cerrar cada vez más las fronteras.

En el caso de la emigración de nicaragüenses a Costa Rica, alcanzar un mínimo de entendimiento en materia de relaciones bilaterales entre Nicaragua y Costa Rica es cada vez más lejano. Los últimos acontecimientos a nivel internacional entre estos dos Estados ponen en tela de duda un posible acuerdo en materia migratoria. Por un lado Costa Rica ha interpuesto una demanda ante el Tribunal Internacional de la Haya en contra de Nicaragua por los derechos de navegación sobre el río San Juan y Nicaragua interpuso una petición ante la Comisión Interamericana de Derechos Humanos por la violación de los derechos humanos de los nicaragüenses en Costa Rica, petición que fue fallada a favor del Estado costarricense. Por lo tanto, mientras estos países vecinos resuelven sus diferencias por la vía del Derecho Internacional, los migrantes nicaragüenses mantienen vivos los flujos migratorios en las fronteras, y ante la imposibilidad de cumplir con los requisitos migratorios, penetran las fronteras de forma irregular. Esta misma situación la viven los inmigrantes extraregionales que alimentan el flujo migratorio sur-norte.

En definitiva, el control y resguardo de las fronteras significa para un Estado su seguridad. Sin embargo, mientras la población de un Estado determinado no tenga plenamente garantizados sus derechos humanos fundamentales, su seguridad no será plena mediante el resguardo militar de sus fronteras, pues se requieren más que muros y leyes duras para conseguir la seguridad de un país. Un Estado es seguro cuando cada uno de sus elementos integrantes lo es. Para el territorio, su seguridad consiste en su integridad, para el gobierno, en su estabilidad, para los habitantes, en el respeto a sus derechos humanos fundamentales (Faúndez Ledesma, 1999:98). 


\subsection{Voces de migrantes}

Más allá de los estándares internacionales, la soberanía de los Estados y las mismas políticas migratorias, los y las migrantes entienden que cruzar la frontera les abre puertas a mejores oportunidades de vida. En este último apartado presentamos, en palabras de la población migrante, la percepción de ellos sobre la frontera.

Inmigrante colombiano:

Yo pienso que entre más pobres son nuestros países es más complicado migrar, porque lo pueden matar, robar. Entre más necesidad tengan los países es contradictorio, pero es más difícil. ${ }^{30}$

Inmigrante cubano:

La verdad es que es bien complicado. Yo no sé si agradecerles a los de migración que me detuvieron en El Salvador porque era bien, bien difícil. Usted sabe que en Cuba no tenemos fronteras porque es una isla. Con esta experiencia que me llevo es bien complicado, primero de regular el paso y en general lo conflictivo que se vuelve todo eso en países fronterizos. Una experiencia bien extraña, después de todo me alegro porque he escuchado de asaltos que hay en la frontera de El Salvador para allá, muertes hasta de tiros en la frontera de México y Estados Unidos. Yo he oído comentarios de personas que se han tirado del tren.

Grupo de inmigrantes peruanos:

Países como Estados Unidos se aprovechan de los recursos naturales de nuestros países y nosotros no podemos ir a trabajar, porque lo que nosotros queremos es ir a trabajar no queremos ir a hacerle daño a nadie, queremos darles una mejor vida a nuestras familias. Nosotros no queremos robarle, queremos trabajar. Ahora, si uno entra a un país y comete fechorías y comete algo ilegal deben ser sancionados. Porque solamente los mexicanos tienen esa facilidad. A ellos, llegan, les ofrecen contratos muchas oportunidades. Porque sólo los mexicanos tienen esa oportunidad y no los cubanos, los centroamericanos, nosotros no tenemos esa oportunidad. Qué cosa tienen ellos, creo que eso sería como una ayuda humanitaria para nuestros países que están económicamente mal y creo que esa sería una ayuda para nuestros países, Ecuador, Colombia, Perú, Nicaragua. ${ }^{31}$

"Coyotes":

Para mi conocimiento debe de existir una ley que regule las fronteras. Porque si no, entrara el que le diera la gana. Uno entraría a robar a otro país y así. Me parece que tiene que haber un control. Ideay esto es que hay leyes y todo, siempre pasan cosas que no deberían de ocurrir, cuánto más si no existiesen..$^{32}$

\section{Puesto Fronterizo de Peñas Blancas}

En las fronteras suele coexistir una variedad de actores. En el puesto fronterizo de Peñas Blancas se encuentran: agentes u oficiales de migración, agentes de aduanas, oficiales de la Policía Nacional y el Ejército, vendedores(as) ambulantes, cambistas de dinero conocidos también como “coyotes”, tramitadores que ayudan a los viajeros con sus trámites migratorios 
y documentos de paso vehicular, viajeros(as), transportistas, etc.

La Policía Nacional en el puesto fronterizo de Peñas Blancas ha empleado ciertas medidas para hacer el paso por la frontera más seguro y ordenado. Una de estas medidas es el establecimiento de un horario de seguridad de siete de la mañana a tres de la tarde. En el lado costarricense de la frontera se encuentran también los mismos actores, pero no circulan vendedores ambulantes, sino vendedores de sellos (pago de la Cruz Roja) y cambistas de dinero. También están los "ciclo taxis" que prestan los servicios de transporte a los viajeros que van o vienen transbordando con mucho equipaje. La Policía Nacional ha tomado medidas para regular este servicio a fin de evitar que se cometan robos a los migrantes. Generalmente, los migrantes que usan estos servicios son los que viajan transbordando desde Costa Rica a Nicaragua (generalmente los y las inmigrantes que regresan a Nicaragua de visita o por algún asunto familiar y traen consigo regalos o enseres para sus familiares). Las autoridades policiales en la frontera de Peñas Blancas se han reunido con los dueños de los ciclo taxis orientándoles que presten sus servicios a todos los migrantes y no sólo a los que vienen con mucho equipaje, con los cuales pueden ganar más. También están en comunicación con las personas que venden comida o lavan carros para que de forma ordenada y segura vendan sus servicios en la frontera respetando el horario establecido. He comprobado personalmente y el control que ejerce la Policía Nacional en el servicio de los ciclo taxis para que se respete el horario de seguridad establecido.

\section{Algunas recomendaciones para abordar el fenómeno de la migración irregular}

El fenómeno de la migración irregular no debe abordarse solamente como un hecho que violenta la seguridad del Estado, debe afrontarse y tratarse como una relación de interdependencia que surge entre países - a nivel regional o extraregional -, y en este sentido, se deben crear políticas que favorezcan el respeto de los derechos humanos de las poblaciones que emigran buscando mejores oportunidades de empleo y niveles de vida. El fenómeno migratorio implica beneficios y obligaciones para ambos países, siempre y cuando se creen y apliquen políticas migratorias que den respuesta a las necesidades de los países involucrados.

Los programas de prevención del tráfico de migrantes y la trata de personas deben considerar la adecuada documentación de los nacionales en el Estado de origen, la expedición de pasaportes seguros, el conocimiento por parte de la población de los canales regulares de migración y los riesgos del tráfico de migrantes. El Estado de Nicaragua debe priorizar una política nacional que mejore la situación de indocumentación de los ciudadanos en el propio país. Por ejemplo, mejorar y agilizar el trámite de la cédula de identidad. La Red Nicaragüense de la Sociedad Civil para las Migraciones ha planteado la propuesta al Consejo Supremo Electoral para que, en conjunto con los Consulados de Nicaragua en Costa Rica, se elabore un trabajo que facilite la entrega de los documentos de identidad a muchos nicaragüense en Costa Rica.

Es necesaria y urgente una tipificación amplia y coherente con la realidad del fenómeno migratorio del tráfico ilícito de migrantes, de la trata de personas y los delitos conexos a estos ilícitos, como pueden ser el narcotráfico o el tráfico de armas. Para esto será necesario 
mejorar las normas que aborden tanto el delito de la trata de personas como el tráfico ilícito de migrantes. Pero además será necesario fortalecer las capacidades institucionales y humanas para contrarrestar estos delitos, capacitar de forma constante a las autoridades que tienen la función de controlar y sancionar el tráfico ilícito de migrantes, sobre todo para desarrollar destrezas que permitan distinguir al migrante del traficante, ya que se puede estar protegiendo al traficante en el CRM. Asimismo, se debe garantizar una protección consular efectiva.

Tanto el gobierno como las organizaciones de la sociedad civil podrían iniciar un tipo de acompañamiento a la población del CRM, brindándole ayuda humanitaria y realizando monitoreos frecuentes sobre la situación de los derechos humanos de los inmigrantes retenidos. El gobierno debe de asignar los recursos humanos y materiales necesarios para brindar una mejor atención a la población migrante y de esta forma cumplir con lo que establece la Ley 240-513, al menos en el período de detención de la población migrante en situación de irregularidad migratoria.

Dado que el flujo migratorio sur-norte involucra a toda la región centroamericana, es necesario que se fortalezca la coordinación en la creación y aplicación de las políticas migratorias en la región. En el caso específico del flujo migratorio sur-sur, los Estados de Nicaragua y Costa Rica deben de mejorar sus relaciones y crear una verdadera política que no vaya dirigida sólo a controlar el flujo de los migrantes regulares o irregulares sino a combatir el crimen del tráfico ilícito de migrantes y la trata de personas. En este sentido, será necesario estudiar a profundidad las particularidades del fenómeno y establecer legislaciones que combatan las redes organizadazas de traficantes y tratantes.

El 31 de octubre de 2007 se dio el traspaso de la presidencia Pro Témpore de la Conferencia Regional sobre Migraciones (CRM) del gobierno de Estados Unidos a la República de Honduras. Esto representa una oportunidad para los gobiernos de la región para fortalecer la coordinación regional en el abordaje del fenómeno migratorio, y la prevención y lucha contra los delitos de trata de personas y tráfico ilícito de migrantes.

\section{Notas}

1 Adoptada mediante resolución A/RES/55/25 del 15 de noviembre de 2000 en la LV Sesión de la Asamblea General de las Naciones Unidas.

2 Adoptado mediante resolución A/RES/55/25 del 15 de noviembre de 2000 en la LV Sesión de la Asamblea General de las Naciones Unidas.

3 Convención Internacional sobre la Protección de los Derechos de Todos los Trabajadores Migratorios y de sus Familiares 1990, ONU. Entró en vigor en julio de 2003. Nicaragua ratificó este instrumento en 2005.

4 Proyecto del Código Penal de Nicaragua.

5 Ley 240, Ley de Control de Tráfico de Migrantes Ilegales, 20 de noviembre de 1996, La Gaceta 220 (1996) 51895192.

6 Las disposiciones se refieren a los dueños, administradores y empleados de hoteles, hospedajes, pensiones o negocios similares, que den alojamiento a extranjeros que se encuentren en el país en situación irregular. El Arto. 15 se refiere a las personas naturales o jurídicas que contraten los servicios profesionales o laborales de extranjeros en condición de ilegalidad.

7 El Arto. 13 de la Ley 240 se refiere a las empresas transportadoras y particulares que transporten extranjeros hacia Nicaragua 
que no dispongan de visa nicaragüense.

8 Ley 240-513, Ley de Reforma y Adiciones a la Ley 240, Ley de Control de Tráfico de Migrantes llegales, aprobada el 26 de noviembre de 2004, La Gaceta 20 (2005).

9 Gaceta № 172 del 05 de septiembre de 2005.

10 Véase en el Decreto 57-2005 la lista de países ubicados por categorías. Véase también el Decreto 70- 2005, aprobado el 12 de octubre de 2005 y publicado en la Gaceta No. 200 del 17 de octubre de 2005.

11 Acuerdos de Libre Visado. Disponibles en: http://www.migracion.gob.ni/leyes/librevisado.html, 2004.

12 Entrevista a Carlos Mora, Sub-Comisionado de la Policía Nacional. Peñas Blancas, 18 de julio de 2005.

13 En el Cono Sur, Argentina se ha caracterizado como país de destino de migrantes limítrofes (Paraguay, Uruguay y Bolivia) (Grimson, 2005).

14 Cárdenas se localiza en la zona Sur del país, a 162 kilómetros de Managua. Limita al Norte con el lago Cocibolca y al Sur con Costa Rica. Es colindante al Este con San Carlos, Río San Juan y al Oeste con Rivas y San Juan del Sur. Tiene una extensión territorial de 163 kilómetros y 5,038 habitantes, de los cuales, 4,199 viven en el campo. Está compuesta por 16 comarcas.

15 Entrevista al Director de Migración en la Frontera de Peñas Blancas. 18 de julio de 2005.

16 Entrevista a un migrante mexicano y a un migrante cubano en el CRM, Managua. 08 de julio de 2005.

17 Entrevista al Sub-Comisionado de la Policía Nacional. Peñas Blancas, 18 de julio de 2005.

18 Entrevista al Sub-Comisionado de la Policía Nacional. Peñas Blancas, 18 de julio de 2005.

19 Informe presentado por la Relatora Especial, Sra. Gabriela Rodríguez Pizarro, de conformidad con la resolución 1999/44 de la Comisión de Derechos Humanos, 6 de enero de 2000. Párrafo 88.

20 Entrevista a un "coyote" en la frontera de Peñas Blancas, Rivas. 05 de julio de 2005.

21 Red Nicaragüense de la Sociedad Civil para las Migraciones (septiembre de 2004). Foro Nacional: "Por una Ley Migratoria que tutele los Derechos Humanos". Managua.

22 Entrevista al Jefe del CRM, DGME. Managua, 08 de julio de 2005.

23 Entrevista a un migrante colombiano, CRM, Managua. 08 de julio de 2005.

24 Entrevista al Jefe del CRM, DGME. Managua, 08 de julio de 2005.

25 Entrevista al Sub-Comisionado de la Policía Nacional. Peñas Blancas, 18 de julio de 2005.

26 Entrevista al Sub-Comisionado de la Policía Nacional. Peñas Blancas, 18 de julio de 2005.

27 Convención de Viena de Relaciones Consulares (Arto. 36) y la Convención Americana sobre los Derechos Humanos (Arto. $8 \mathrm{CADH}$ ).

28 Declaración Universal de los Derechos Humanos (Arto. 9), Pacto Internacional de los Derechos Civiles y Políticos (Arto. 9.1, 9.5, 11), la Declaración Americana de los Derechos y Deberes del Hombre (Arto. XXV de) y la Convención Americana de Derechos Humanos.

29 Por ejemplo, la malla en la frontera Sur de España, donde el gobierno español ha reforzado las vallas perimetrales de Ceuta y Melilla con cuchillas que han producido gravísimas lesiones a inmigrantes subsaharianos; el muro (972 metros de largo) construido por Costa Rica para evitar el ingreso de migrantes nicaragüenses indocumentados al territorio costarricense; 0 el muro que Estados Unidos pretende construir en su frontera con México.

30 Entrevista a un migrante colombiano en el CRM. Managua, 08 de julio de 2005.

31 Entrevista a migrantes peruanos en el CRM. Managua, 08 de julio 2005.

32 Entrevista a un "coyote" en la frontera de Peñas Blancas, 18 de julio de 2005.

\section{Referencias bibliográficas}

ASAMBLEA CONSTITUYENTE. (1987). "Constitución Política de la República de Nicaragua”, 19 de noviembre de 1986, La Gaceta 94, 120-136.

ASAMBLEA NACIONAL. (2005). Decreto No 57-2005, 5 octubre 2005, La Gaceta 172. (2005). "Ley 240-513, Ley de Reforma y Adiciones a la Ley 240, Ley de Control de tráfico de Migrantes Ilegales" 26 de noviembre de 2004, La Gaceta 20. (2004). "Decreto No. 66-2004: Adhesión al protocolo contra el tráfico ilícito de migrantes por tierra, mar y aire, que complementa la Convención de las Naciones Unidas contra 
la delincuencia organizada transnacional”, La Gaceta. 134, 3525-3526.

(2004). "Decreto No.107-2004, Decreto de adhesión a la Convención Internacional sobre la protección de los Derechos de todos los Trabajadores Migratorios y de sus Familiares", 28 de septiembre de 2004, La Gaceta 191, 5430.

_ (2004). "Decreto. No. 3925 De aprobación de la adhesión al protocolo para prevenir, reprimir y sancionar la trata de personas, especialmente mujeres y niños, que complementa la convención de las Naciones Unidas contra la delincuencia organizada transnacional”, La Gaceta 134, 3523-3524.

(2004). "Decreto No 115 -99”, 11 de octubre de 1999, La Gaceta 204, 4802.

— (2001). "Ley 406, Código Procesal Penal de la República de Nicaragua”, 13 de noviembre de 2001, La Gaceta 243 y 244.

(1996). "Ley 240, Ley de Control de tráfico de Migrantes ilegales", 20 de noviembre de 1996, La Gaceta 220, 5189-5192.

CIDEHUM. (2003). Derechos Humanos de los Migrantes en Centroamérica. Prevención del Tráfico de Migrantes y la Trata de Personas. San José:CIDEHUM.

FAÚNDEZ LEDESMA, H. (1999), El Sistema Interamericano de Protección de los Derechos Humanos. San José: Instituto Interamericano de Derechos Humanos.

GONZÁLEZ, H. (2005). Mecanismos de Promoción y Protección de los Derechos Humanos de los nicaragüenses en Costa Rica. Tesis de Licenciatura en Derecho. Managua: Facultad de Ciencias Jurídicas, Universidad Centroamericana.

GONZÁLEZ, H. \& PÉREZ, X. (2005). Consulta sobre documentación en el Municipio de Cárdenas, Rivas. Red Nicaragüense de la Sociedad Civil Para las Migraciones. 10 de junio. Mimeo.

GRIMSON, A. (2005). "Nuevas xenofobias, nuevas políticas en Argentina", ponencia presentada en el Seminario-Taller "Migración Transfronteriza en América Central, Perspectivas Regionales" dado en la Ciudad Universitaria Rodrigo Facio, UCR, del 03 al 05 de febrero de 2005, Costa Rica.

HENRÍQUEZ, O. \& HERNÁNDEZ, I. (2004). “Nicas Martirizados”. En El Nuevo Diario, 05 de enero, Managua.

JUNTA NACIONAL DE GOBIERNO. (1974). “Decreto 297, Código Penal de la República de Nicaragua”, 1 de abril de 1974, La Gaceta 96.

KAUFFER, E. (s.f.) Dinámica Migratoria en la Frontera Sur. Entre peligros y polleros, la travesía de los indocumentados centroamericano. Disponible en: http://www.ecosur. mx/Difusi\%C3\%B3n/ecofronteras/ecofrontera/ecofront19/pdf/polleros.pdf .[Consultada en marzo de 2006].

LAMBERG, L. (2002). Síntesis del Informe Final sobre Tráfico de Mujeres y Niños para Fines de Explotación Sexual en las Américas. Comisión Interamericana de Mujeres. Disponible en http://www.oas.org/CIM/Spanish/Proy.Traf.Res.Inf.Final.htm. [ConsultadA el 31 marzo de 2005].

MÁRMORA, L. (2002). Las políticas de migraciones internacionales. Buenos Aires: Editorial Paidós.

MENDOZA LÓPEZ, M. (mayo de 2004). Trata de Personas, Particularmente de Mujeres, en Centroamérica y República Dominicana. Disponible en: http://www.gtzgenero.org. ni/_publicacion/TRATA\%20PERSONAS\%20FINAL.pdf [Consultada el 22 de septiembre de 2005].

OCAM; OIM; OIT/IPEC. (2004). Folleto informativo: Diferencias entre tráfico ilícito de 
migrantes y la trata de personas menores edad. Disponible en: www.esnips.com. [Consultada el 30 de marzo 2006.

ORGANIZACIÓN INTERNACIONAL DE LAS MIGRACIONES - OIM. (s.f.) Lucha contra el tráfico de personas. Disponible en: http://www.iom.int/en/who/main service areas counter espanol.html [Consultada en abril de 2005].

PÉREZ SOLÍS, R. (2005). "Yerros judiciales abonan a la trata de personas", en La Prensa Gráfica, 13 de abril.

PNUD. (2004). "Informe sobre desarrollo humano 2004. La libertad cultural en el mundo diverso de hoy”. Programa de las Naciones Unidas para el Desarrollo.

REAL INSTITUTO ELCANO. (2005). El factor hispano: los efectos de la inmigración latinoamericana a EE.UU.y España. Disponible en: http://www.realinstitutoelcano org [Consultado en marzo de 2006].

ROMERO, E. (2004). "Nicaragua frente a la trata de blancas”. En La Prensa, 16 Junio.

SICA. (2005). XXVI Reunión ordinaria de Jefes de Estado y de gobierno de los países del Sistema de la Integración Centroamericana (SICA), Tegucigalpa, Honduras, 30 de junio de 2005. Disponible en: http://www.sieca.org.gt/Publico/Doctos_y_Publicaciones/ Publicaciones/Boletin_Informativo/BOLETIN_No21_ANO_7.htm 